(C) 2022, The Authors. Published by Elsevier Inc. and Fass Inc. on behalf of the American Dairy Science Association ${ }^{\circledR}$. This is an open access article under the CC BY license (http://creativecommons.org/licenses/by/4.0/).

\title{
Site-directed mutation of $\beta$-galactosidase from Streptococcus thermophilus for galactooligosaccharide-enriched yogurt making
}

\author{
J. C. Zhao, ㅇ Y. L. Mu, X. Y. Gu, X. N. Xu, T. T. Guo, and J. Kong* ${ }^{\circ}$ \\ State Key Laboratory of Microbial Technology, Shandong University, Qingdao, 266237, P. R. China
}

\section{ABSTRACT}

$\beta$-Galactosidase is one of the most important enzymes used in dairy processing. It converts lactose into glucose and galactose, and also catalyzes galactose to form galactooligosaccharides (GOS), so-called prebiotics. However, most of the $\beta$-galactosidases from the starter cultures have low transgalactosylation activities, the process that results in galactose accumulation in yogurt. Here, a site-directed mutation strategy was attempted, to genetically modify $\beta$-galactosidase from Streptococcus thermophilus. Out of 28 Strep. thermophilus strains, a $\beta$-galactosidase gene named bga $Q$, encoded for high $\beta$-galactosidase hydrolysis activity (BgaQ), was cloned from the strain Strep. thermophilus SDMCC050237. It was 3,081 bp in size, with 1,027 deduced amino acid residuals, which belonged to the GH2 family. After replacing the $\mathrm{Tyr}^{801}$ and $\mathrm{Pro}^{802}$ around the active sites of $\mathrm{BgaQ}$ with $\mathrm{His}^{801}$ and $\mathrm{Gly}^{802}$, the GOS synthesis of the generated mutant protein BgaQ-8012 increased from $20.5 \%$ to $26.7 \%$ at $5 \%$ lactose, and no hydrolysis activity altered obviously. Subsequently, the purified BgaQ or BgaQ-8012 was added to sterilized milk inoculated with 2 starters from Strep. thermophilus SDMCC050237 and Lactobacillus delbrueckii ssp. bulgaricus ATCC11842. The GOS yields with added BgaQ or BgaQ-8012 increased to 5.8 and $8.3 \mathrm{~g} / \mathrm{L}$, respectively, compared with a yield of $3.7 \mathrm{~g} / \mathrm{L}$ without enzymes added. Meanwhile, the addition of the BgaQ or BgaQ8012 reduced the lactose content by $49.3 \%$ and $54.4 \%$ in the fermented yogurt and shortened the curd time. Therefore, this study provided a site-directed mutation strategy for improvement of the transgalactosylation activity of $\beta$-galactosidase from Strep. thermophilus for GOS-enriched yogurt making.

Key words: $\beta$-galactosidase, Streptococcus thermophilus, transgalactosylation, site-directed mutangenesis

Received June 22, 2021.

Accepted November 1, 2021.

*Corresponding author: kongjian@sdu.edu.cn

\section{INTRODUCTION}

Yogurt, one of the most popular fermented dairy products, is typically fermented using 2 starter cultures, from Streptococcus thermophilus and Lactobacillus delbrueckii ssp. bulgaricus (Horiuchi et al., 2009). However, most yogurt starter cultures only metabolize the glucose moiety of lactose and release the galactose in the extracellular medium, resulting in significant amounts of galactose accumulation (Hols et al., 2005; Zhang et al., 2020b). Lactose is not recommended for individuals with symptom of lactose intolerance, which is a common disease in more than half of the world's population (Husain, 2010). In addition, amounts of galactose also reduce the quality of fermented dairy products. For low-sugar yogurt making, several attempts have been made to isolate galactose-positive wild-type Strep. thermophilus strains or to co-culture starter cultures with other Lactobacillus species (Robitaille et al., 2007; Anbukkarasi et al., 2014; Sørensen et al., 2016; Zhang et al., 2020b). Also, arabinose isomerase has been used during milk fermentation to convert galactose into the low-calorie sweetener tagatose (Rhimi et al., 2011).

$\beta$-Galactosidase, commonly known as lactase (EC 3.2.1.23), is widely used in the food industry to improve the sweetness, solubility, and flavor of dairy products (Oliveira at al., 2011; Saqib et al., 2017). The commercially used $\beta$-galactosidases are mainly from Aspergillus oryzae and Kluyveromyces lactis (Horiuchi et al., 2009; Husain, 2010; Saqib et al., 2017; Serey et al., 2021). Many bacterial strains also have the capacity to produce $\beta$-galactosidases, including Bifidobacterium longum, Bacillus circulans, and Lactobacillus spp. (Boon et al., 2000; Hsu et al., 2007; Iqbal et al., 2011; Nguyen et al., 2012). In addition to hydrolysis activity, $\beta$-galactosidase also has transgalactosylation activity to catalyze galactose to form galactooligosaccharide (GOS), which has benefits for human health (Torres et al., 2010; Xin et al., 2019; Lu et al., 2020). To increase GOS yields, several strategies have been successfully attempted to improve the transgalactosylation activity of $\beta$-galactosidase (Gao et al., 2019; Qin et al., 2019). 
Streptococcus thermophilus is one of the most important starters for fermented dairy products with high $\beta$-galactosidase hydrolysis activity (Anbukkarasi et al., 2014; Zhang et al., 2020a). However, the transgalactosylation activity of the enzyme in Strep. thermophilus is normally low, resulting in galactose accumulation in yogurt. In this study, a $\beta$-galactosidase $\mathrm{BgaQ}$ was isolated from Strep. thermophilus SDMCC050237. After the prediction of structural and active sites via bioinformatics analysis, genetic modification of BgaQ through a site-directed mutagenesis was performed, and the GOS biosynthesis of the generated mutated enzyme in $5 \%$ lactose and reconstituted skim milk (RSM) medium were determined. The aim of this study was to improve the transgalactosylation activity of $\beta$-galactosidase from Strep. thermophilus, to catalyze galactose into GOS for manufacture of GOS-enriched yogurt.

\section{MATERIALS AND METHODS}

\section{Bacterial Strains, Plasmids, and Cultivation Conditions}

The strains and plasmids used in this study are listed in Supplemental Table S1 (https://zenodo.org/record/ 5720718\#.YZzi9sVBw2w). Streptococcus thermophilus strains were cultured in M17 broth (Oxoid) supplemented with $1 \%$ lactose at $42^{\circ} \mathrm{C}$. The $L b$. bulgaricus strain ATCC11842 was grown statically in de Man, Rogosa, and Sharpe medium at $37^{\circ} \mathrm{C}$. Escherichia coli strains were grown aerobically in Luria-Bertani medium at $37^{\circ} \mathrm{C}$. If necessary, kanamycin was supplemented to a final concentration of $30 \mu \mathrm{g} / \mathrm{mL}$.

\section{Determination of Hydrolysis and Transgalactosylation Activities of $\beta$-Galactosidases from Strep. thermophilus}

Cells of Strep. thermophilus strains cultured in lactose-supplemented M17 broth at $42^{\circ} \mathrm{C}$ for $12 \mathrm{~h}$ were harvested by centrifugation at $6,000 \times g$ for $5 \mathrm{~min}$ at $4^{\circ} \mathrm{C}$, washed twice with PBS ( $\mathrm{pH} 7.4$ ), and suspended in PBS. The cells were disrupted by a cell homogenizer and centrifuged at $10,000 \times g$ for $10 \mathrm{~min}$ at $4^{\circ} \mathrm{C}$, and the supernatant was used to assay the hydrolysis and transgalactosylation activities of the $\beta$-galactosidases as described previously (Lu et al., 2015; Xin et al., 2019). Briefly, the hydrolysis activity of the $\beta$-galactosidase was performed in $200-\mu \mathrm{L}$ mixtures containing $50 \mu \mathrm{L}$ of the cell supernatant and $150 \mu \mathrm{L}$ of lactose solution $(200 \mathrm{~g} / \mathrm{L})$ dissolved in PBS (pH 7.4), and incubated at $50^{\circ} \mathrm{C}$ for $10 \mathrm{~min}$. Reactions were stopped by heating at $100^{\circ} \mathrm{C}$ for $5 \mathrm{~min}$. The amount of glucose released in the reaction mixture was detected using a glucose assay kit (Robio). One unit of $\beta$-galactosidase activity was defined as the amount of enzyme releasing $1 \mathrm{mmol}$ of D-glucose per minute.

The transgalactosylation reaction was performed in $100-\mu \mathrm{L}$ mixtures containing $50 \mu \mathrm{L}$ of the cell supernatant and $50 \mu \mathrm{L}$ of lactose solution $(200 \mathrm{~g} / \mathrm{L})$ dissolved in PBS (pH 7.4) at $42^{\circ} \mathrm{C}$ for $4 \mathrm{~h}$, and then stopped by heating at $100^{\circ} \mathrm{C}$ for $5 \mathrm{~min}$. Five microliters of the reaction solution was spotted onto thin-layer chromatography plates (Merck). The sugars were separated by a developing solvent consisting of n-butanol, isopropyl alcohol, acetic acid, and water (38.9\%:27.8\%:11.1\%:22.2\%). Subsequently, the plates were air-dried and sprayed with a chromogenic agent consisting of acetone-anilinephosphoric acid (50:1:5 by volume) containing $0.018 \%$ (wt/vol) diphenylamine. After incubation at $105^{\circ} \mathrm{C}$ for 5 min, the bands were visualized and then photographed (Lu et al., 2015).

\section{Molecular Manipulation}

All molecular manipulations in this study were performed as described previously (Xin et al., 2019). Plasmids from E. coli were extracted using a Plasmid Mini Kit (Omega). Taq polymerase, restriction enzymes, and T4 DNA ligase were purchased from TaKaRa and used according to the standard procedures.

For the biochemical property analysis of $\beta$-galactosidase, the gene bgaQ was PCR amplified from the genomic DNA of Strep. thermophilus SDMCC050237 with primers bgaQ F (5'-CATGCCATGGACATGACTGAAAAAATTCAAA-3'; underlining indicates the Nco I site) and bgaQ R (5'-CCGCTCGAGATTTAGTGGTTCAATCATGAAGCTT-3'; underlining indicates the Xho I site). The PCR product was digested with the restriction enzymes Nco I and Xho I and then ligated into the corresponding sites of plasmid pET28a, generating the recombinant plasmid pET28a-bgaQ. After transformation into E. coli BL21 (DE3), the resulting recombinant E. coli BL21 carrying BgaQ was cultured at $37^{\circ} \mathrm{C}$ until cultures' optical density at $600 \mathrm{~nm}$ reached 0.6 ; then $0.1 \mathrm{~m} M$ isopropyl- $\beta$-Dthiogalactoside was added to the medium, and culturing continued for $20 \mathrm{~h}$ at $16^{\circ} \mathrm{C}$ for protein expression. Then the cells of E. coli BL21 carrying BgaQ were harvested by centrifugation at $6,000 \times g$ for $5 \mathrm{~min}$ at $4^{\circ} \mathrm{C}$ and washed twice with PBS. The cells were disrupted by ultrasonic treatment and centrifuged at $10,000 \times g$ for $20 \mathrm{~min}$ at $4^{\circ} \mathrm{C}$ to remove cell debris. The expression of the protein BgaQ was determined on SDS-PAGE gel after purification by nickel-nitrilotriacetic acid (NiNTA) affinity chromatography, according to standard procedures. 


\section{Sequence Analysis and Protein Modeling of the $\beta$-Galactosidase BgaQ}

Sequence identity and similarity searches for the gene bga $Q$ were performed using Blast at NCBI (http:/ / www .blast.ncbi.nlm.nih.gov). Multiple-sequence alignment of BgaQ with other related $\beta$-glucosidase sequences was performed using ClustalX 2.0 (Larkin et al., 2007). The 3-dimensional structure of BgaQ was generated using the Swiss-Model protein modeling server (http: //swissmodel.expasy.org). The topology structure of $\beta$-galactosidase from E. coli (Protein Data Bank identification number 1PX3) was obtained from the RCSB Protein Data Bank (http://www.rcsb.org). The modeled structures were analyzed for the active sites of BgaQ by the Pymol molecular graphics system (http:/ /www.pymol.org). The amino acid sites associated with transgalactosylation activity were found by autodocking using $\beta$-3'-galactosyl-lactose as substrate.

\section{Site-Directed Mutagenesis of the $\beta$-Glucosidase BgaQ}

To genetic modify the transgalactosylation activity, the $\mathrm{Tyr}^{801}$ and $\mathrm{Pro}^{802}$ around the activity sites in BgaQ sequence were predicted and replaced by $\mathrm{His}^{801}$ and Gly ${ }^{802}$ using overlap PCR with the mutagenic primer pairs 8012-forward 5'-ACAACGATCGTGGTGCTGGACATGGATTCGAAATG-3' and 8012-reverse 5'-TCCAGCCTGCCATTTCGAATCCATGTCCAGCACCA-3', with the underlined nucleotides coding the amino acids His and Gly at positions 801 and 802 . After digestion with $N c o I$ and XhoI, the PCR products were ligated into the corresponding sites of the plasmid pET28a, generating the recombinant plasmid pET28-bgaQ-8012, the mutant protein BgaQ-8012 was expressed in E. coli BL21 (DE3) and purified as previously described for BgaQ.

\section{Biochemical Properties of BgaQ and Mutant BgaQ-8012}

The optimal temperature for hydrolysis activities of the purified $\beta$-galactosidase BgaQ and the mutant BgaQ-8012 were determined over the range of 25 to $65^{\circ} \mathrm{C}$. For the thermostability assay, the residual activities of the purified enzymes were measured after incubation from 37 to $60^{\circ} \mathrm{C}$ for $100 \mathrm{~min}$. Three buffer systems, citrate buffer ( $50 \mathrm{~m} M, \mathrm{pH} 5.5)$, sodium phosphate buffer $(50 \mathrm{~m} M, \mathrm{pH} 6.0-8.0)$, and Tris-HCl buffer (50 mM, pH 8.5-10.0), were used to measure the optimal $\mathrm{pH}$ for hydrolysis activity of the $\beta$-galactosidase $\mathrm{BgaQ}$ and the mutant BgaQ- 8012 at $42^{\circ} \mathrm{C}$. The residual activities were measured for $\mathrm{pH}$ stability in various buffers from $\mathrm{pH} 6.0$ to 10.0. For optimization of GOS synthesis conditions, $\mathrm{pH}$ from 6.0 to 8.0 and reaction temperatures from 37 to $60^{\circ} \mathrm{C}$ were adopted.

\section{GOS Biosynthesis with BgaQ and BgaQ-8012}

To simulate the fermentation conditions of yogurt processing, GOS production was measured at $5 \%$ lactose dissolved in PBS $(\mathrm{pH} 6.5)$ at $42^{\circ} \mathrm{C}$, containing $1 \mathrm{U}$ of purified BgaQ or BgaQ-8012, for 240 min. Samples were collected at intervals of $40 \mathrm{~min}$. The GOS in the samples were analyzed by HPLC using an Aminex HPX-87H Carbohydrate Column $(300 \mathrm{~mm} \times 7.8 \mathrm{~mm}$; Bio-Rad) at $65^{\circ} \mathrm{C}$, with a refractive index detector. The mobile phase was deionized water at a flow rate of 0.5 $\mathrm{mL} / \mathrm{min}$. The GOS yield was calculated from the total amount of saccharides eluted at the retention times.

\section{Fermented Milk}

BgaQ and BgaQ-8012 were applied to catalyze GOS synthesis in milk. An RSM medium was prepared by reconstituting skim milk powder $(10 \% \mathrm{wt} / \mathrm{vol})$ with distilled water and sterilized at $115^{\circ} \mathrm{C}$ for $10 \mathrm{~min}$. The 2 starters Strep. thermophilus SDMCC050237 and $L b$. bulgaricus ATCC11842 were cocultured at a ratio of 4:1 in $100 \mathrm{~mL}$ of RSM medium to which $1 \mathrm{U}$ of the purified BgaQ or BgaQ-8012 was added; fermentation without purified $\beta$-galactosidase was used as control. After incubation at $42^{\circ} \mathrm{C}$ for $12 \mathrm{~h}$, the curd time was observed visually, indicating the time at which milk changed from a flowing liquid to an immobile semisolid state. The concentrations of lactose, galactose, and GOS in yogurt were determined via HPLC. The $\mathrm{pH}$, titratable acidity, syneresis, and viable cell counts were detected at the end of fermentation, as described by da Costa et al. (2016) and Li et al. (2017).

\section{Statistical Analysis}

Each experiment was carried out in triplicate, and data are presented as mean \pm standard deviation. Statistical significance between yogurts fermented by traditional starters with or without $\beta$-galactosidase was determined using SPSS version 19.0 (IBM Corp.), with $P<0.05$ considered as statistically significant.

\section{Amino Acid Sequence Accession Numbers}

The $\beta$-galactosidase BgaQ and BgaQ-8012 sequences were deposited in GenBank and assigned the following accession numbers: BgaQ, SAMN20952848; BgaQ8012, SAMN20952849. 


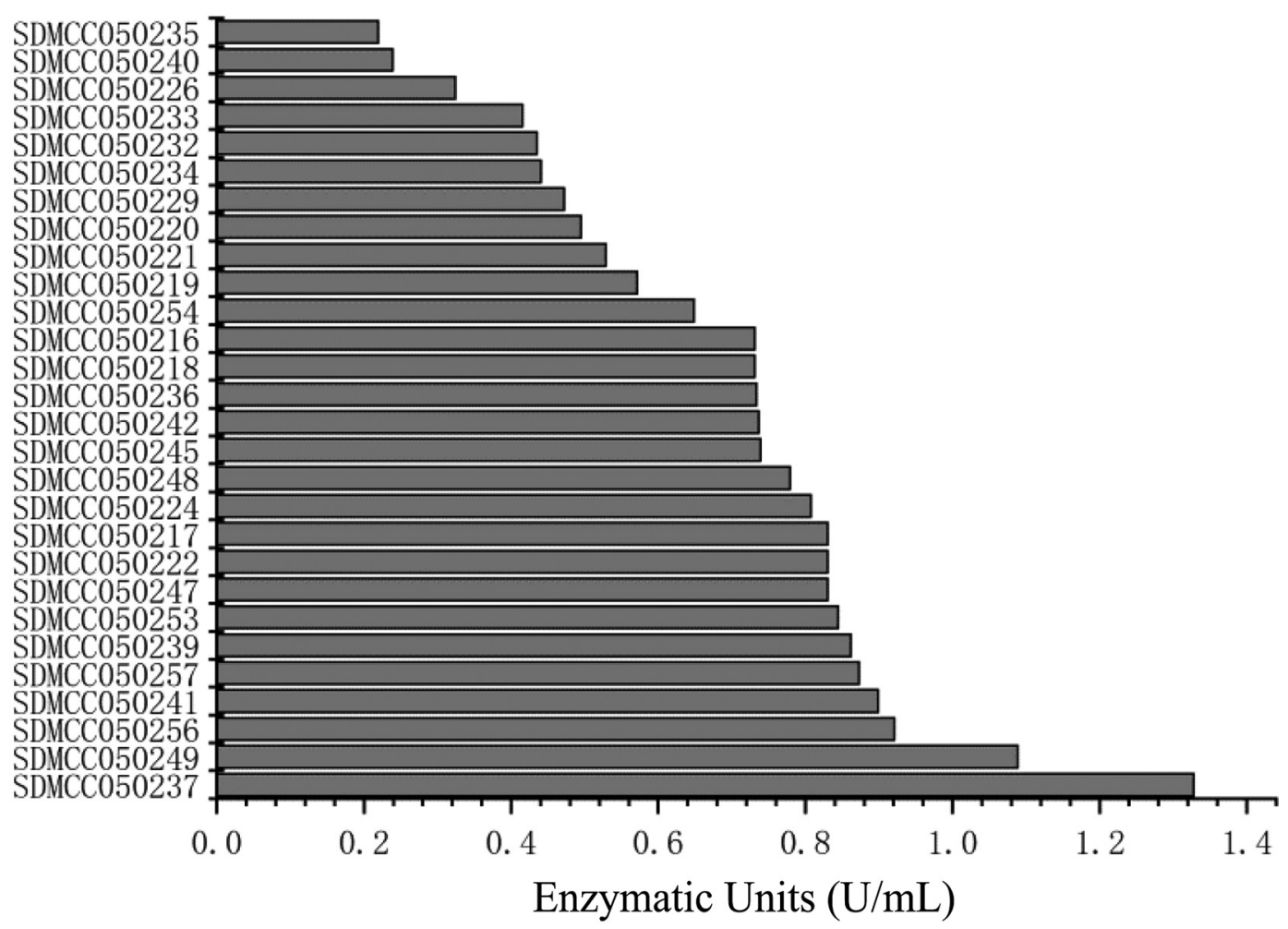

Figure 1. Hydrolytic activities of $\beta$-galactosidases from various Streptococcus thermophilus strains.

\section{RESULTS}

\section{Analysis of Hydrolysis and Transgalactosylation Activities of $\beta$-Galactosidases from Strep. thermophilus}

The hydrolysis and transgalactosylation activities of the $\beta$-galactosidases from 28 Strep. thermophilus strains were determined. Results presented in Figure 1 showed that the hydrolysis activities of $\beta$-galactosidases occurred in a strain-specific manner among the Strep. thermophilus strains tested, and the strain Strep. thermophilus SDMCC050237 exhibited the highest hydrolysis activity, reaching $1.33 \mathrm{U} / \mathrm{mL}$. However, the transgalactosylation activities of the $\beta$-galactosidases from the tested Strep. thermophilus strains appeared relatively low, as observed by small amounts of GOS production (Figure 2). Therefore, the $\beta$-galactosidase (BgaQ) from Strep. thermophilus SDMCC050237 was selected for the following analysis.

\section{Cloning and Site-Directed Mutation of the $\beta$-Galactosidase BgaQ from Strep. thermophilus SDMCC050237}

A $\beta$-galactosidase gene $b g a Q$ was cloned from the Strep. thermophilus SDMCC050237 genome. It was
3,081 bp in length and composed of 1,027 amino acid residues. Multiple-sequence alignment showed that the deduced sequence BgaQ shared $99.5 \%$ and $47.50 \%$ similarities to the $\beta$-galactosidase of Strep. thermophilus CS9 (accession no. CP030927) and $L b$. bulgaricus JCM1002 (accession no. CAI98003), respectively (Supplemental Figure S1, https://zenodo.org/ record/5720758\#.YZzkXsVBw2w). Moreover, 6 of the $\beta$-galactosidase sequences of Strep. thermophilus strains available were retrieved from the GenBank database, and multiple-sequence alignment revealed that those $\beta$-galactosidases were highly conserved (Supplemental Figure S1), exhibiting a $(\beta / \alpha)_{8}$ barrel (TIM barrel) fold consisting of an inner core of 8 parallel $\beta$-strands surrounded by $8 \alpha$-helices, indicating that the BgaQ from Strep. thermophilus SDMCC050237 belonged to the GH2 family.

To improve the transgalactosylation activity of the BgaQ, the catalyzing domain of this enzyme was predicted by comparison with that of the known $\beta$-galactosidase 1PX3 from E. coli. As shown in Figure 3a, the 2 active sites of glutamate, $\mathrm{Glu}^{458}$ and $\mathrm{Glu}^{546}$, were identified in BgaQ, and 10 potential transgalactosylation-related sites around them were provided by autodocking using $\beta$-3'-galactosyl-lactose as substrate (Figure 3a). Sequence alignment of the BgaQ with the high transgalactosylation activities of the 


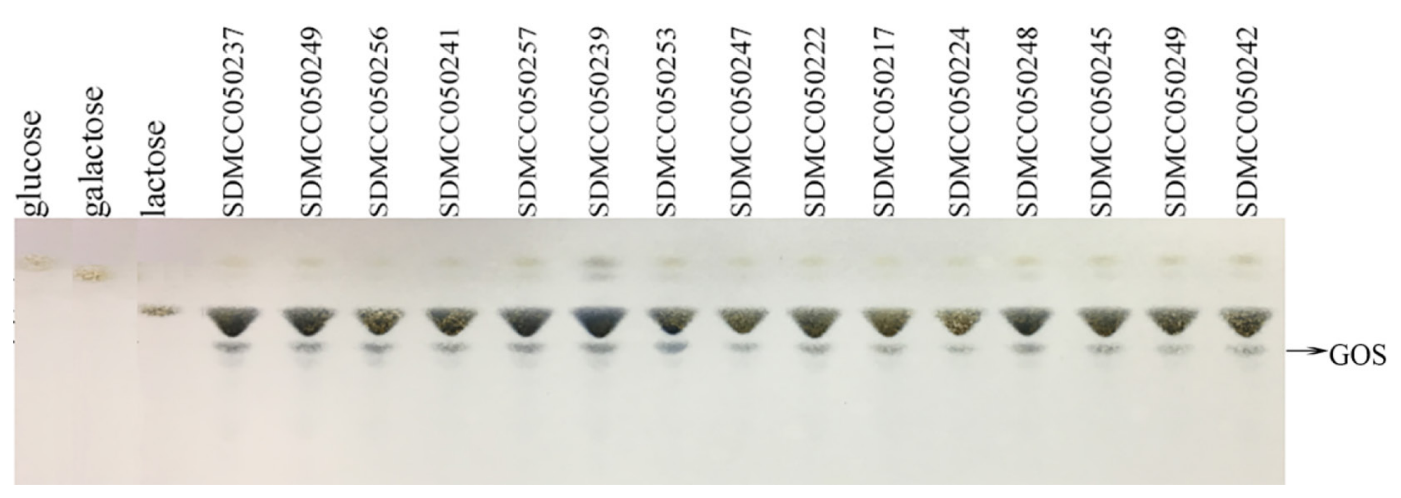

Figure 2. Transgalactosylation activities of various Streptococcus thermophilus strains. GOS = galactooligosaccharide.

$\beta$-galactosidases from other bacteria showed that the amino acid residues $\mathrm{Tyr}^{801}$ and $\mathrm{Pro}^{802}$ around the active sites $\mathrm{Glu}^{458}$ and $\mathrm{Glu}^{546}$ varied significantly in specific strains (Figure 3b), leading us to speculate that the sites $\operatorname{Tyr}^{801}$ and $\operatorname{Pro}^{802}$ were the key sites affecting the transglycosylation activity of the enzyme BgaQ. Thus, the amino acid residues $\mathrm{Tyr}^{801}$ and $\mathrm{Pro}^{802}$ were selected as targets for the site-directed mutagenesis. After replacing the $\mathrm{Tyr}^{801}$ and $\mathrm{Pro}^{802}$ with $\mathrm{His}^{801}$ and Gly ${ }^{802}$ by overlap PCR, and detecting the transgalactosylation activity, the mutant protein BgaQ-8012 was obtained.

\section{Biochemical Characterization of BgaQ and BgaQ-8012}

For biochemical analysis, BgaQ and BgaQ-8012 were expressed in E. coli DE3 and purified by Ni-NTA Column (Qiagen), respectively. The 2 purified protein bands appeared the same size, approximately $113 \mathrm{KD}$, on SDS-PAGE gel, which was in accordance with their theoretical molecular mass (Figure 4). Meanwhile, no statistical difference was detected between the hydrolytic activities of these 2 purified $\beta$-galactosidases. The optimum temperature and $\mathrm{pH}$ of the purified BgaQ8012 were also the same as those of the wild-type en- zyme BgaQ at $50^{\circ} \mathrm{C}$ and 8.5 , respectively (Figure 5). In addition, BgaQ-8012 was shown to be more sensitive to temperature, with only $19 \%$ hydrolytic activity at $50^{\circ} \mathrm{C}$ for 40-min incubation, whereas BgaQ retained 57\% activity under the same conditions (Figure 6). For pH stability, both BgaQ and BgaQ-8012 were more stable in acidic $\mathrm{pH}$, showing maximal stability at $\mathrm{pH} 6.5$.

The transgalactosylation conditions of these 2 purified proteins were detected. As shown in Figure 7a, the optimal $\mathrm{pH}$ for both BgaQ and BgaQ-8012 was 6.5. However, the optimal temperature showed obvious difference, with the optimal temperature of $\mathrm{BgaQ}$ being $50^{\circ} \mathrm{C}$ and $42^{\circ} \mathrm{C}$ for BgaQ-8012 (Figure $7 \mathrm{~b}$ ).

\section{GOS Yields at 5\% Lactose}

To simulate the lactose content of yogurt processing, GOS production was performed at $5 \%$ lactose dissolved in PBS ( $\mathrm{pH}$ 6.5) at $42^{\circ} \mathrm{C}$, containing purified BgaQ or BgaQ-8012, for 240 min. Results showed that the GOS yields in these 2 reaction mixtures increased with prolonged time. The GOS yield of BgaQ- 8012 was obviously higher than that of BgaQ during the reaction processes: the maximal GOS yield of BgaQ was about $20.5 \%$ at 120 min, compared with $26.7 \%$ for BgaQ-8012
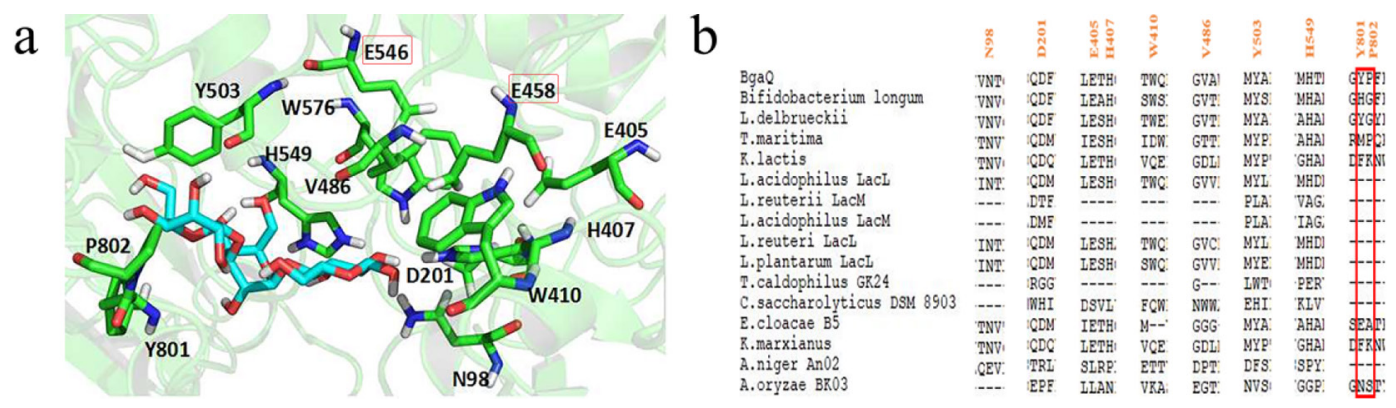

Figure 3. Autodocking analysis of the transgalactosylation-related sites of BgaQ, the $\beta$-galactosidase from Streptococcus thermophilus SDMCC050237. (a) Results of autodocking between BgaQ and $\beta$-3'-galactosyl-lactose; (b) results of the multiple-sequence alignments of transgalactosylation-related sites of BgaQ. 
M T BgaQ BgaQ-8012

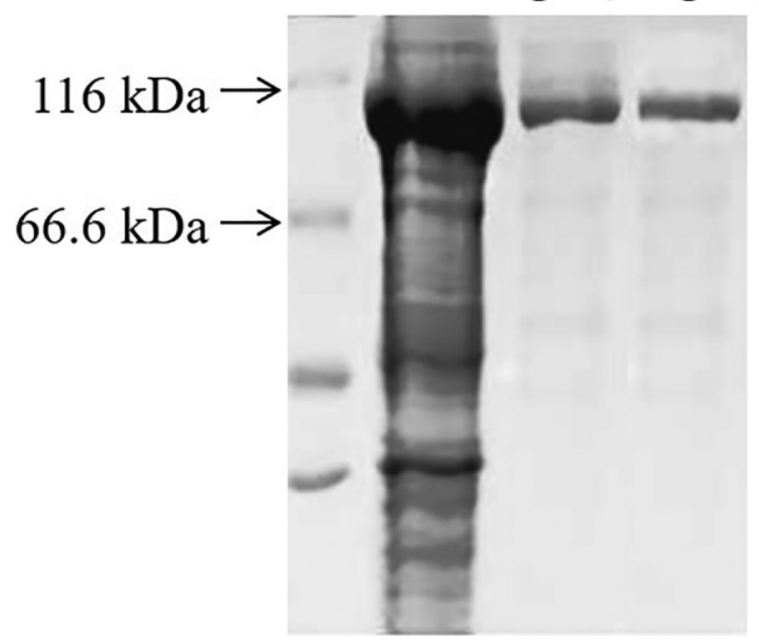

Figure 4. SDS-PAGE analysis of the purified BgaQ (the $\beta$-galactosidase from Streptococcus thermophilus SDMCC050237) and Bga-8012 (the mutant enzyme of BgaQ). $\mathrm{M}=$ protein marker; $\mathrm{T}=$ total proteins in the lysate.

at $160 \mathrm{~min}$, indicating that the transgalactosylation activity of the BgaQ increased with the site-directed mutagenesis (Figure 8).

\section{Properties of Yogurt Fermented with BgaQ and BgaQ-8012}

Purified BgaQ or BgaQ-8012 were added to the RSM medium in which 2 traditional starters, Strep. thermophilus SDMCC050237 and Lb. bulgaricus ATCC11842, were inoculated. After incubation at $42^{\circ} \mathrm{C}$ for $12 \mathrm{~h}$, the contents of lactose and total sugar were significantly reduced by $38.6 \%$ and $16.5 \%$ (incubated with 2 traditional starters), $49.3 \%$ and $26.5 \%$ (incubated with 2 traditional starters+ BgaQ), and $54.4 \%$ and $40.1 \%$ (incubated with 2 traditional starters + BgaQ-8012), respectively (Table 1). Meanwhile, the GOS yields in yogurt fermented with 2 traditional starters and with added BgaQ and BgaQ-8012 were 3.7 $\mathrm{g} / \mathrm{L}, 5.8 \mathrm{~g} / \mathrm{L}$, and $8.3 \mathrm{~g} / \mathrm{L}$ (Table 1). The GOS yields of the mutant enzyme BgaQ-8012 increased compared with the wild enzyme BgaQ (Table 1). However, the galactose contents in all samples increased, particularly in the yogurts with the added $\beta$-galactosidase, BgaQ and BgaQ-8012, suggesting that the low $\mathrm{pH}$ in yogurt processing or low lactose content limited the GOS synthesis of the $\beta$-galactosidases.

Fermented milk performance analysis showed that the addition of the $\beta$-galactosidase BgaQ or BgaQ-8012 shortened the curd time significantly compared with the traditional yogurt starters, and there was no significant difference in $\mathrm{pH}$, titratable acidity, and water-holding capacity of yogurt between them (Table 2). In addition, the viable cell counts of Strep. thermophilus SDMCC050237 and Lb. bulgaricus ATCC 11842 in all the groups reached $8 \log \mathrm{cfu} / \mathrm{mL}$ (Supplemental Table S2, https://zenodo.org/record/5720726\#.YZzk9sVBw2w).

\section{DISCUSSION}

$\beta$-Galactosidase plays a main role in the conversion of lactose into glucose and galactose in dairy products (Sangwan et al., 2015; Lu et al., 2020), as well as in the production of GOS based on its transgalactosylation property (Liu et al., 2017; Rico-Díaz et al., 2017). Most studies have focused on GOS biosynthesis from high concentrations of lactose (Song et al., 2013; Yu and O'Sullivan, 2014; Sangwan et al., 2015; Cao et al., 2019), while little attention has been paid to GOS production in fermented milk, where the low lactose
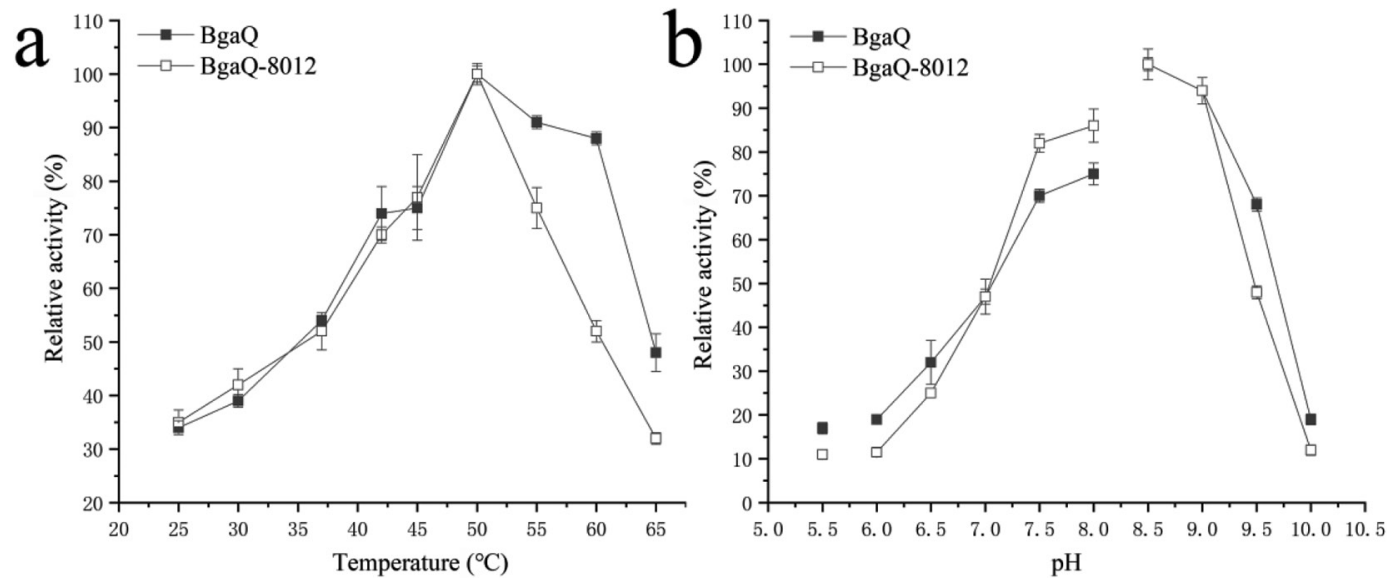

Figure 5. Optimum temperature (a) and optimum $\mathrm{pH}$ (b) for BgaQ (the $\beta$-galactosidase from Streptococcus thermophilus SDMCC050237) and BgaQ-8012 (the mutant enzyme of BgaQ). Error bars indicate SD. 

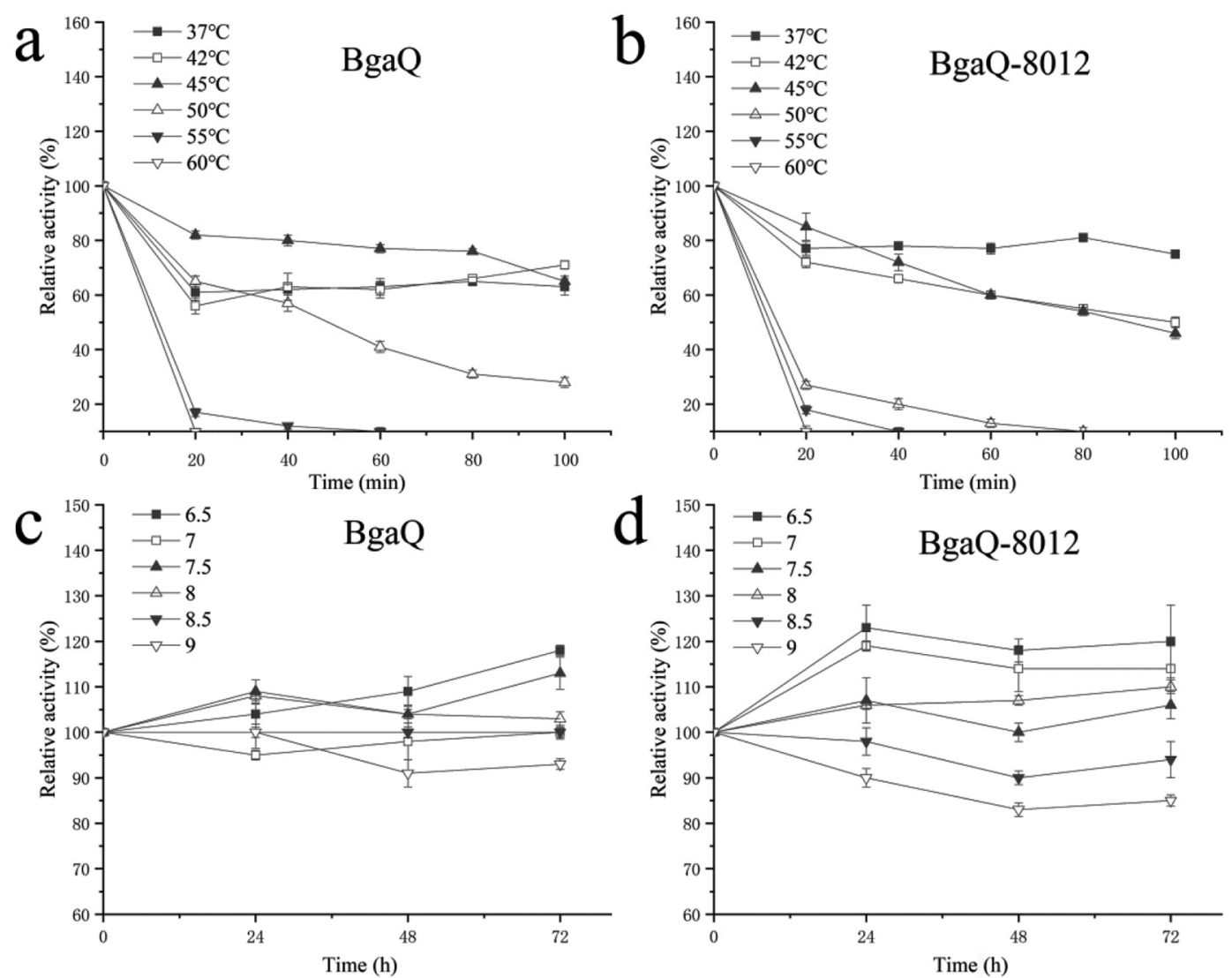

Figure 6. Temperature stability of BgaQ (the $\beta$-galactosidase from Streptococcus thermophilus SDMCC050237, a) and BgaQ-8012 (the mutant enzyme of BgaQ, b), and pH stability of BgaQ (c) and BgaQ-8012 (d). Error bars indicate SD.

content (around 5\% wt/vol) is not appropriate for optimal transgalactosylation activity (Rodriguez-Colinas et al., 2014). Because the 2 traditional starters of Strep. thermophilus and Lb. bulgaricus metabolize only the glucose moiety of lactose and release the galactose, resulting in significant amounts of galactose accumu- lation in yogurt, production of low-sugar yogurt is of increasing interest in the fermented dairy industry. In this study, a novel strategy was adopted to convert residual galactose to GOS through modification of $\beta$-galactosidase from Strep. thermophilus. As expected, a mutant enzyme BgaQ-8012, modified by site-directed
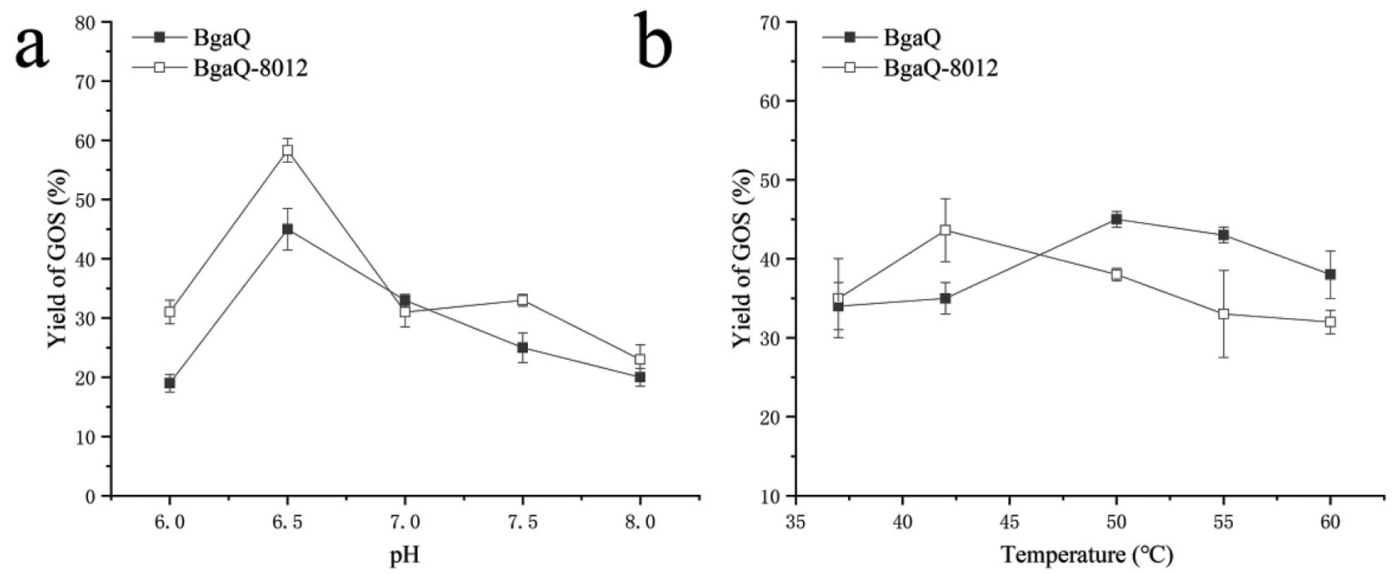

Figure 7. Effects of various $\mathrm{pH}(\mathrm{a})$ and temperatures (b) on the galactooligosaccharide (GOS) yields of the purified proteins. BgaQ $=$ the $\beta$-galactosidase from Streptococcus thermophilus SDMCC050237; BgaQ-8012 = the mutant enzyme of BgaQ. Error bars indicate SD. 
Table 1. Residual sugar content in fermented milks ${ }^{1}$

\begin{tabular}{|c|c|c|c|c|c|}
\hline Group $^{2}$ & $\begin{array}{c}\text { Lactose } \\
(\mathrm{mmol} / \mathrm{kg})\end{array}$ & $\begin{array}{l}\text { Galactose } \\
(\mathrm{mmol} / \mathrm{kg})\end{array}$ & $\begin{array}{l}\text { GOS yield } \\
\quad(\mathrm{g} / \mathrm{L})\end{array}$ & $\begin{array}{c}\text { Percentage of } \\
\text { lactose reduction }(\%)\end{array}$ & $\begin{array}{l}\text { Percentage of total } \\
\text { sugar reduction (\%) }\end{array}$ \\
\hline RSM medium & $114.35 \pm 3.56$ & - & - & - & — \\
\hline Traditional starters & $70.09 \pm 2.66^{\mathrm{a}}$ & $50.53 \pm 1.89^{\mathrm{a}}$ & $3.7 \pm 0.09^{\mathrm{a}}$ & $38.5^{\mathrm{a}}$ & $16.54^{\mathrm{a}}$ \\
\hline Traditional starters + BgaQ-8012 & $49.37 \pm 1.18^{\mathrm{c}}$ & $60.79 \pm 2.42^{\mathrm{c}}$ & $8.3 \pm 0.13^{\mathrm{c}}$ & $54.4^{\mathrm{c}}$ & $40.14^{\mathrm{c}}$ \\
\hline
\end{tabular}

${ }^{\mathrm{a}-\mathrm{c}}$ Different superscripts indicate significant differences $(P<0.05)$ between yogurt fermented by the 2 traditional starters with BgaQ and BgaQ8012.

${ }^{1}$ Values are presented as mean $\pm \mathrm{SD}$ of 3 individual experiments $(\mathrm{n}=3)$; - indicates data not shown. The percentages of total sugar reduction were calculated by the molar weight of monosaccharides. GOS = galactooligosaccharide.

${ }^{2} \mathrm{RSM}=$ reconstituted skim milk. Traditional starters $=$ Streptococcus thermophilus SDMCC050237 and Lactobacillus delbrueckii ssp. bulgaricus ATCC11842. BgaQ = the $\beta$-galactosidase from Strep. thermophilus SDMCC050237; BgaQ-8012 = the mutant enzyme of BgaQ.

mutagenesis from the $\beta$-galactosidase BgaQ in Strep. thermophilus SDMCC050237, showed high GOS synthesis ability using $5 \%$ lactose as substrate, as well as in yogurt processing. Therefore, this study provides an efficient strategy to improve the transgalactosylation activity of $\beta$-galactosidase and could be used for GOSenriched yogurt making.

Site-directed mutagenesis is an invaluable technique to modify genes for the analysis of the structural and functional properties of proteins. Several enzyme variants have been successfully obtained using this strategy, which display enhanced transgalactosylation activity of $\beta$-galactosidase or thermal stability compared with the corresponding wild-type enzymes (Yang et al., 2015; Rico-Díaz et al., 2017). But the key of this technique is to identify the targeting mutated sites. Bioinformation

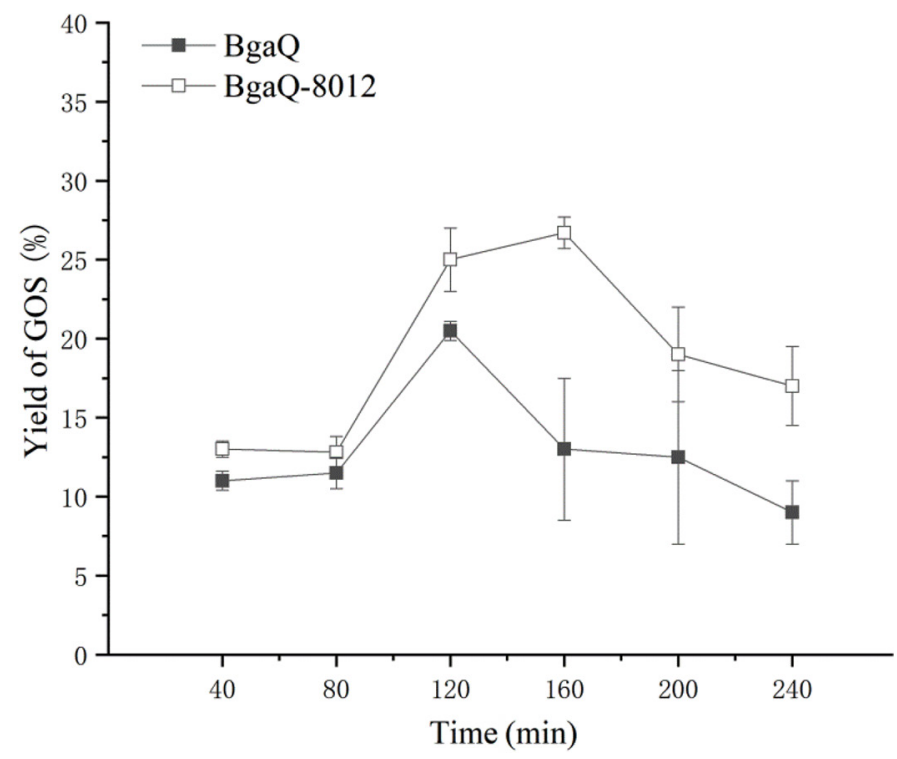

Figure 8. Curves of galactooligosaccharide (GOS) biosynthesized by purified BgaQ (the $\beta$-galactosidase from Streptococcus thermophilus SDMCC050237) and BgaQ-8012 (the mutant enzyme of BgaQ) in 5\% lactose as substrate. Error bars indicate SD. software and internet sites provide the possibility of prediction and analysis of the active sites of enzymes. Using these tools, the potential transgalactosylation-related sites of $\mathrm{Tyr}^{801}$ and $\mathrm{Pro}^{802}$ around the active sites of $\mathrm{Glu}^{458}$ and $\mathrm{Glu}^{546}$ in BgaQ were identified (Figure 3a). On the basis of results reported previously, indicating that aromatic amino acids around the active sites can reduce the efficiency of enzyme binding to the receptor substrate (Bultema et al., 2014), the aromatic amino acid $\mathrm{Tyr}^{801}$, which binds to the acceptor substrate, was replaced by $\mathrm{His}^{801}$. In consideration of the doubledisplacement reaction of transgalactosylation, including the formation of a glycosylated enzyme reaction intermediate and its deglycosylation either by water molecule (hydrolysis) or by other acceptor (transgalactosylation), it was logical that a reduction in hydrolysis would be beneficial for the transgalactosylation reaction (Qin et al., 2019). Therefore, the amino acid Pro ${ }^{802}$ was substituted by $\mathrm{Gly}^{802}$, which could be achieved by reducing the water activity around the active sites. As a result, no obvious difference in hydrolytic activities appeared between BgaQ and the mutant BgaQ-8012. As expected, the transgalactosylation activity of the mutant BgaQ-8012 was enhanced, with GOS yield from $20.5 \%$ to $26.7 \%$ in $5 \%$ lactose as substrate (Figure 8), which was in agreement with previous reports (Bultema et al., 2014; Qin et al., 2019). Meanwhile, the optimal temperature for GOS production decreased from $50^{\circ} \mathrm{C}$ to $42^{\circ} \mathrm{C}$, a promising temperature for yogurt fermentation. These results further demonstrate that site-directed mutagenesis is an effective tool for improvement of the transgalactosylation activity of $\beta$-galactosidase in Strep. thermophilus.

To investigate the GOS synthesis of the mutant enzyme BgaQ-8012 in yogurt processing, the purified enzymes were added to RSM medium in combination with the 2 traditional starters Strep. thermophilus SDMCC050237 and Lb. bulgaricus ATCC 11842. As anticipated, the addition of BgaQ or BgaQ-8012 improved the GOS yield, suggesting that the $\beta$-galactosidases 
Table 2. Physicochemical characteristics of fermented milks ${ }^{1}$

\begin{tabular}{lcccc}
\hline Group $^{2}$ & $\begin{array}{c}\text { Curd } \\
\text { time }(\mathrm{h})\end{array}$ & $\mathrm{pH}$ & $\begin{array}{c}\text { Titratable } \\
\text { acidity }\left({ }^{\circ} \mathrm{T}\right)\end{array}$ & $\begin{array}{c}\text { Syneresis } \\
(\%)\end{array}$ \\
\hline Traditional starters & $7 \pm 0^{\mathrm{a}}$ & $3.78 \pm 0.02$ & $107.6 \pm 2.31$ & $50.9 \pm 0.01$ \\
Traditional starters + BgaQ & $6 \pm 0^{\mathrm{b}}$ & $3.77 \pm 0.02$ & $109.5 \pm 1.67$ & $51.9 \pm 0.01$ \\
Traditional starters + BgaQ-8012 & $6 \pm 0^{\mathrm{b}}$ & $3.78 \pm 0.02$ & $108.7 \pm 2.07$ & $51.4 \pm 0.01$ \\
\hline
\end{tabular}

${ }^{\mathrm{a}, \mathrm{b}}$ Different superscripts indicate significant differences $(P<0.05)$ between yogurt fermented by the 2 traditional starters with BgaQ and BgaQ-8012.

${ }^{1}$ Values are presented as mean $\pm \mathrm{SD}$ of 3 individual experiments $(\mathrm{n}=3)$.

${ }^{2}$ Traditional starters $=$ Streptococcus thermophilus SDMCC050237 and Lactobacillus delbrueckii ssp. bulgaricus ATCC11842. BgaQ = the $\beta$-galactosidase from Strep. thermophilus SDMCC050237; BgaQ-8012 = the mutant enzyme of BgaQ.

from Strep. thermophilus have abilities to synthesize GOS at low levels of lactose content. In addition, the GOS yield of the mutant enzyme BgaQ-8012 increased from $5.8 \mathrm{~g} / \mathrm{L}$ to $8.3 \mathrm{~g} / \mathrm{L}$ compared with the wild-type enzyme BgaQ (Table 1), which indicated that the mutant enzyme BgaQ-8012 was more suitable for GOSenriched yogurt making. Compared with the addition of artificial GOS to yogurt directly, the addition of BgaQ or BgaQ-8012 also significantly reduced the contents of lactose and total sugar, as has been previously reported (Ruiz-Matute et al., 2012; Rodriguez-Colinas et al., 2014).

Acidification and curding in a short incubation time are crucial for yogurt making. The fermented milk performance analysis showed that the addition of the BgaQ and BgaQ-8012 shortened the curd time in yogurt processing, due to the $\beta$-galactosidases $\mathrm{BgaQ}$ and BgaQ-8012 added exogenously to accelerate the hydrolysis of lactose into galactose and glucose, which rapidly promoted the growth of the 2 traditional starters Strep. thermophilus SDMCC050237 and Lb. bulgaricus ATCC11842 at the beginning of fermentation processing, produced more lactic acid to lower the $\mathrm{pH}$, and subsequently facilitated the acidification processes. It has been reported that cocultures of $L b$. bulgaricus 2038 and Strep. thermophilus 1131 in lactosehydrolyzed milk resulted in increased cell numbers of Lb. bulgaricus 2038 (Yamamoto et al., 2021), but no obvious differences of the cell counts in yogurts with or without addition of the purified enzymes were observed in our study (Supplemental Table S2, https:/ /zenodo.org/record/5720726\#.YZzk9sVBw2w). Along with the growth of the 2 starters Strep. thermophilus SDMCC050237 and Lb. bulgaricus ATCC11842, the $\mathrm{pH}$ dropped quickly, and the lactose content in milk was reduced, which might inhibit the enzyme activities of the $\beta$-galactosylases BgaQ and BgaQ-8012, in turn, with more galactose accumulation in the medium. However, the lactose and total sugar contents were decreased obviously; this phenomenon was also as described previously (Oliveira at al., 2011; Ruiz-Matute et al., 2012; Rodriguez-Colinas et al., 2014). Therefore, exogenous addition of the $\beta$-galactosidases from Strep. thermophilus, with high transgalactosylation activity, contributed to GOS-enriched yogurt making.

\section{ACKNOWLEDGMENTS}

This work was supported by grants from the National Natural Science Foundation of China (No. 31871767; Beijing) and the National Key Research and Development Program of China (2017YFD0400300; Beijing). The authors have not stated any conflicts of interest.

\section{REFERENCES}

Anbukkarasi, K., T. UmaMaheswari, T. Hemalatha, D. K. Nanda, P. Singh, and R. Singh. 2014. Preparation of low galactose yogurt using cultures of $\mathrm{Gal}^{+}$Streptococcus thermophilus in combination with Lactobacillus delbrueckii ssp. bulgaricus. J. Food Sci. Technol. 51:2183-2189. https://doi.org/10.1007/s13197-014-1262-5.

Boon, M. A., A. E. M. Janssen, and K. van 't Riet. 2000. Effect of temperature and enzyme origin on the enzymatic synthesis of oligosaccharides. Enzyme Microb. Technol. 26:271-281. https://doi .org/10.1016/S0141-0229(99)00167-2.

Bultema, J. B., B. J. H. Kuipers, and L. Dijkhuizen. 2014. Biochemical characterization of mutants in the active site residues of the $\beta$-galactosidase enzyme of Bacillus circulans ATCC 31382. FEBS Open Bio 4:1015-1020. https://doi.org/10.1016/j.fob.2014.11.002.

Cao, P., L. Wu, Z. Wu, D. Pan, X. Zeng, Y. Guo, and L. Lian. 2019. Effects of oligosaccharides on the fermentation properties of $\mathrm{Lac}$ tobacillus plantarum. J. Dairy Sci. 102:2863-2872. https://doi.org/ $10.3168 /$ jds.2018-15410.

da Costa, M. P., B. da Silva Frasao, B. R. C. da Costa Lima, B. L. Rodrigues, and C. A. Conte Jr.. 2016. Simultaneous analysis of carbohydrates and organic acids by HPLC-DAD-RI for monitoring goat's milk yogurts fermentation. Talanta 152:162-170. https:// doi.org/10.1016/j.talanta.2016.01.061.

Gao, X., J. Wu, and D. Wu. 2019. Rational design of the beta-galactosidase from Aspergillus oryzae to improve galactooligosaccharide production. Food Chem. 286:362-367. https://doi.org/10.1016/j .foodchem.2019.01.212.

Hols, P., F. Hancy, L. Fontaine, B. Grossiord, D. Prozzi, N. LeblondBourget, B. Decaris, A. Bolotin, C. Delorme, S. Dusko Ehrlich, E. Guedon, V. Monnet, P. Renault, and M. Kleerebezem. 2005. New insights in the molecular biology and physiology of Streptococcus thermophilus revealed by comparative genomics. FEMS Microbiol. Rev. 29:435-463. https://doi.org/10.1016/j.femsre.2005.04.008.

Horiuchi, H., N. Inoue, E. Liu, M. Fukui, Y. Sasaki, and T. Sasaki. 2009. A method for manufacturing superior set yogurt under re- 
duced oxygen conditions. J. Dairy Sci. 92:4112-4121. https://doi .org/10.3168/jds.2008-1747.

Hsu, C. A., S. L. Lee, and C. C. Chou. 2007. Enzymatic production of galactooligosaccharides by $\beta$-galactosidase from Bifidobacterium longum BCRC 15708. J. Agric. Food Chem. 55:2225-2230. https:/ /doi.org/10.1021/jf063126+.

Husain, Q. 2010. $\beta$-Galactosidases and their potential applications: A review. Crit. Rev. Biotechnol. 30:41-62. https://doi.org/10.3109/ 07388550903330497.

Iqbal, S., T. H. Nguyen, H. A. Nguyen, T. T. Nguyen, T. Maischberger, R. Kittl, and D. Haltrich. 2011. Characterization of a heterodimeric GH2 $\beta$-galactosidase from Lactobacillus sakei Lb790 and formation of prebiotic galacto-oligosaccharides. J. Agric. Food Chem. 59:3803-3811. https://doi.org/10.1021/jf103832q.

Larkin, M. A., G. Blackshields, N. P. Brown, R. Chenna, P. A. McGettigan, H. McWilliam, F. Valentin, I. M. Wallace, A. Wilm, R. Lopez, J. D. Thompson, T. J. Gibson, and D. G. Higgins. 2007. Clustal W and Clustal X version 2.0. Bioinformatics 23:2947-2948. https://doi.org/10.1093/bioinformatics/btm404.

Li, C., J. Song, L. Y. Kwok, J. Wang, Y. Dong, H. Yu, Q. Hou, H. Zhang, and Y. Chen. 2017. Influence of Lactobacillus plantarum on yogurt fermentation properties and subsequent changes during postfermentation storage. J. Dairy Sci. 100:2512-2525. https://doi .org/10.3168/jds.2016-11864.

Liu, Y., Z. Chen, Z. Jiang, Q. Yan, and S. Yang. 2017. Biochemical characterization of a novel $\beta$-galactosidase from Paenibacillus barengoltzii suitable for lactose hydrolysis and galactooligosaccharides synthesis. Int. J. Biol. Macromol. 104:1055-1063. https://doi .org/10.1016/j.ijbiomac.2017.06.073.

Lu, L., L. Guo, K. Wang, Y. Liu, and M. Xiao. 2020. $\beta$-Galactosidases: A great tool for synthesizing galactose-containing carbohydrates. Biotechnol. Adv. 39:107465. https://doi.org/10.1016/j.biotechadv .2019.107465.

Lu, L., L. Xu, Y. Guo, D. Zhang, T. Qi, L. Jin, G. Gu, L. Xu, and M. Xiao. 2015. Glycosylation of phenolic compounds by the sitemutated $\beta$-galactosidase from Lactobacillus bulgaricus L3. PLoS One 10:e0121445. https://doi.org/10.1371/journal.pone.0121445.

Nguyen, T. T., H. A. Nguyen, S. L. Arreola, G. Mlynek, K. DjinovicCarugo, G. Mathiesen, T. H. Nguyen, and D. Haltrich. 2012. Homodimeric $\beta$-galactosidase from Lactobacillus delbrueckii subsp. bulgaricus DSM 20081: Expression in Lactobacillus plantarum and biochemical characterization. J. Agric. Food Chem. 60:1713-1721. https://doi.org/10.1021/jf203909e.

Oliveira, C., P. M. Guimaraes, and L. Domingues. 2011. Recombinant microbial systems for improved $\beta$-galactosidase production and biotechnological applications. Biotechnol. Adv. 29:600-609. https: //doi.org/10.1016/j.biotechadv.2011.03.008.

Qin, Z., S. Li, X. Huang, W. Kong, X. Yang, S. Zhang, L. Cao, and Y. Liu. 2019. Improving galactooligosaccharide synthesis efficiency of $\beta$-galactosidase Bgal1-3 by reshaping the active site with an intelligent hydrophobic amino acid scanning. J. Agric. Food Chem. 67:11158-11166. https://doi.org/10.1021/acs.jafc.9b04774.

Rhimi, M., H. Chouayekh, I. Gouillouard, E. Maguin, and S. Bejar. 2011. Production of D-tagatose, a low caloric sweetener during milk fermentation using L-arabinose isomerase. Bioresour. Technol. 102:3309-3315. https://doi.org/10.1016/j.biortech.2010.10.078.

Rico-Díaz, A., M.-E. Álvarez-Cao, J.-J. Escuder-Rodríguez, M.-I. González-Siso, M. E. Cerdán, and M. Becerra. 2017. Rational mutagenesis by engineering disulphide bonds improves Kluyveromyces lactis beta-galactosidase for high-temperature industrial applications. Sci. Rep. 7:45535. https://doi.org/10.1038/srep45535.

Robitaille, G., S. Moineau, D. St-Gelais, C. Vadeboncoeur, and M. Britten. 2007. Galactose metabolism and capsule formation in a recombinant strain of Streptococcus thermophilus with a galactosefermenting phenotype. J. Dairy Sci. 90:4051-4057. https://doi .org/10.3168/jds.2007-0140.

Rodriguez-Colinas, B., L. Fernandez-Arrojo, A. O. Ballesteros, and F. J. Plou. 2014. Galactooligosaccharides formation during enzymat- ic hydrolysis of lactose: Towards a prebiotic-enriched milk. Food Chem. 145:388-394. https://doi.org/10.1016/j.foodchem.2013.08 .060 .

Ruiz-Matute, A. I., M. Corzo-Martínez, A. Montilla, A. Olano, P. Copovi, and N. Corzo. 2012. Presence of mono-, di- and galactooligosaccharides in commercial lactose-free UHT dairy products. J. Food Compos. Anal. 28:164-169. https://doi.org/10.1016/j.jfca 2012.06.003.

Sangwan, V., S. K. Tomar, B. Ali, R. R. Singh, and A. K. Singh. 2015. Production of $\beta$-galactosidase from Streptococcus thermophilus for galactooligosaccharides synthesis. J. Food Sci. Technol. 52:42064215. https://doi.org/10.1007/s13197-014-1486-4.

Saqib, S., A. Akram, S. A. Halim, and R. Tassaduq. 2017. Sources of $\beta$-galactosidase and its applications in food industry. 3 Biotech 7:79. https://doi.org/10.1007/s13205-017-0645-5.

Serey, M., C. Vera, C. Guerrero, and A. Illanes. 2021. Immobilization of Aspergillus oryzae $\beta$-galactosidase in cation functionalized agarose matrix and its application in the synthesis of lactulose. Int. J. Biol. Macromol. 167:1564-1574. https://doi.org/10.1016/j ijbiomac.2020.11.110.

Song, T.-S., K.-S. Lee, S.-B. Kang, S.-H. Yoo, J.-I. Lee, and S.-S. Yoon. 2013. Synthesis of galactooligosaccharides in the cheese whey-based medium by a lactase from Lactobacillus paracasei YSM0308. Han-gug Chugsan Sigpum Hag-hoeji 33:565-571. https: //doi.org/10.5851/kosfa.2013.33.5.565.

Sørensen, K. I., M. Curic-Bawden, M. P. Junge, T. Janzen, and E. Johansen. 2016. Enhancing the sweetness of yoghurt through metabolic remodeling of carbohydrate metabolism in Streptococcus thermophilus and Lactobacillus delbrueckii ssp. bulgaricus. Appl. Environ. Microbiol. 82:3683-3692. https://doi.org/10.1128/AEM $.00462-16$.

Torres, D. P. M., M. P. Goncalves, J. A. Teixeira, and L. R. Rodrigues. 2010. Galacto-oligosaccharides: Production, properties, applications, and significance as prebiotics. Compr. Rev. Food Sci. Food Saf. 9:438-454. https://doi.org/10.1111/j.1541-4337.2010.00119.x.

Xin, Y., T. Guo, Y. Zhang, J. Wu, and J. Kong. 2019. A new $\beta$-galactosidase extracted from the infant feces with high hydrolytic and transgalactosylation activity. Appl. Microbiol. Biotechnol. 103:8439-8448. https://doi.org/10.1007/s00253-019-10092-x.

Yamamoto, E., R. Watanabe, T. Ichimura, T. Ishida, and K. Kimura. 2021. Effect of lactose hydrolysis on the milk-fermenting properties of Lactobacillus delbrueckii ssp. bulgaricus 2038 and Streptococcus thermophilus 1131. J. Dairy Sci. 104:1454-1464. https://doi.org/10 .3168/jds.2020-19244.

Yang, Y., X. Zhang, Q. Yin, W. Fang, Z. Fang, X. Wang, X. Zhang, and Y. Xiao. 2015. A mechanism of glucose tolerance and stimulation of GH1 $\beta$-glucosidases. Sci. Rep. 5:17296. https://doi.org/10 $.1038 / \mathrm{srep} 17296$.

Yu, L., and D. J. O'Sullivan. 2014. Production of galactooligosaccharides using a hyperthermophilic $\beta$-galactosidase in permeabilized whole cells of Lactococcus lactis. J. Dairy Sci. 97:694-703. https:/ /doi.org/10.3168/jds.2013-7492.

Zhang, J., M. Liu, J. Xu, Y. Qi, N. Zhao, and M. Fan. 2020a. First insight into the probiotic properties of ten Streptococcus thermophilus strains based on in vitro conditions. Curr. Microbiol. 77:343-352. https://doi.org/10.1007/s00284-019-01840-3.

Zhang, S. S., Z. S. Xu, L. H. Qin, and J. Kong. 2020b. Low-sugar yogurt making by the co-cultivation of Lactobacillus plantarum WCFS1 with yogurt starter cultures. J. Dairy Sci. 103:3045-3054. https://doi.org/10.3168/jds.2019-17347.

\section{ORCIDS}

J. C. Zhao @ https://orcid.org/0000-0002-1793-7209

J. Kong ๑ https://orcid.org/0000-0002-2872-2078 